\title{
LAVH versus NDVH for benign gynaecological diseases: an experience in tertiary care hospital in Uttarakhand
}

\author{
Goswami $D^{1}$, Kumari $\mathbf{N}^{2}$, Gupta $\mathbf{V}^{3}$, Chaudhary $\mathrm{P}^{4}$ \\ ${ }^{1}$ Dr. Divya Goswami, Associate Professor, ${ }^{2}$ Dr. Nidhi Kumari, Assistant Professor, ${ }^{3}$ Dr. Vineeta Gupta, Professor and \\ Head, ${ }^{4}$ Dr. Priyanka Chaudhary, Assistant Professor. All are affiliated with Department of Obstetrics and Gynaecology, \\ Shri Guru Ram Rai Institute of Medical and Health Sciences and Shri Mahant Indiresh Hospital Dehradun, Uttarakhand, \\ India
}

Address for correspondence: Dr. Divya Goswami, Email: divyagoswamisgrr@rediffmail.com

\begin{abstract}
Introduction: To study the outcome of Non descent vaginal hysterectomy NDVH, Laparoscopic assisted vaginal hysterectomy LAVH in benign gynaecological conditions and to determine the feasibility of both the routes in terms of safety and simplicity, indications of surgery, intraoperative and postoperative analysis. Methods: The present study is retrospective study of 86 cases of NDVH and LAVH from January 2015 to February 2016 in department of obstetrics and gynecology in Shri Guru Ram Rai Institute of Medical And Health Sciences and Shri Mahant Indiresh Hospital, Dehradun Uttarakhand. Result: Among 86 cases undergoing NDVH and LAVH the most common indication of surgery was Fibroid and DUB. The intraoperative complication rate in NDVH was more compared to LAVH. The operative time and intraoperative blood loss was significantly lower in NDVH group with $p<0.001$. Conclusion: The present study concludes that NDVH can be safely offered to patients with benign gynecological conditions. LAVH can be offered as a synergistic surgery in cases where difficulty in operative dissection is anticipated.
\end{abstract}

Keywords: Non descent vaginal hysterectomy (NDVH), Laparoscopic assisted vaginal hysterectomy (LAVH), uterus debulking, Hysterectomy

\section{Introduction}

Hysterectomy is one of the most common gynecological surgeries performed worldwide [1]. There are various routes available for performing hysterectomy which include abdominal, vaginal, and laparoscopic or with robotic assistance [2]. Abdominal hysterectomy is the most commonly performed surgery with 70:30 ratio for abdominal versus vaginal route [3]. The value study gave the impression that Laparoscopic assisted vaginal hysterectomy LAVH was associated with more blood loss, ureteric and bladder injury and anaesthetic complications as compared to abdominal and vaginal routes $[4,5]$.

Despite the conclusions of this trial, LAVH is gaining ground fast due to the obvious advantage of direct visualization of uterus and adnexa prior to any operative dissection. Non descent vaginal hysterectomy NDVH

Manuscript received $14^{\text {th }}$ March 2016

Reviewed: $26^{\text {th }}$ March 2016

Author Corrected: $18^{\text {th }}$ April 2016

Accepted for Publication 30 $30^{\text {th }}$ April 2016 can be performed in properly selected patients with the advantage of less operative and anaesthetic complications as compared to abdominal hysterectomy [6]. Despite the proven advantage of NDVH there is a definite hesitation amongst gynecologists to perform it, the reasons include technical difficulty, inability to perform oophorectomy etc. Both LAVH and NDVH stand out as better routes for performing hysterectomy when compared to abdominal hysterectomy.

LAVH and NDVH are desirable in the state of Uttarakhand since the health resources are limited because of the geographical terrain of the region. Outcome data of these procedures in a tertiary care centre catering to such patients would be helpful for both clinicians and patients to consider either LAVH or NDVH as an approach for hysterectomy.

This study would also guide regarding the comparative outcome of LAVH and NDVH. 


\section{Material and Method}

The present study is a retrospective record based study of 86 cases that underwent NDVH or LAVH from January 2015 to February 2016 in in Shri Guru Ram Rai Institute of Medical And Health Sciences and Shri Mahant Indiresh Hospital, Dehradun Uttarakhand at Obstetrics and gynecology department. The aim of study was to compare and contrast the outcome of NDVH and LAVH for benign gynecological condition.

All these patients were admitted in gynecology department after thorough examination and were subjected to routine preoperative investigations. Patients who had multiple medical disorders or more than one previous caesarean sections were excluded from the study. All the patients were assessed for the size and mobility of uterus. After all the preoperative work up the patients were either subjected to NDVH or LAVH depending upon patient's discretion after discussion with the operating surgeon. Patients undergoing NDVH were given either spinal or epidural anesthesia.

The operative technique included circumferential incision around cervix followed by cutting pubo-vesicocervical ligament and pushing the bladder up. Both anterior and posterior pouches were opened. Uterosacral and cardinal ligament were clamped, cut, and transfixed close to the cervix.

The uterine vessel were clamped and cut after which various debulking procedure were used as and when required. After delivery of uterus surgery was performed in the routine manner.

Patient undergoing LAVH were given general anesthesia. Primary port was put either in umbilical area or in supraumbilically depending upon the size of uterus. Two or three accessory ports were put. The fundal structures were coagulated and cut using harmonic probe. The uterovesical fold was opened and bladder pushed down. Where necessary infundibulopelvic ligament were coagulated and cut to remove the ovary.

Both the groups of patients were studied for the following variables age, parity, past medical and surgical history. Intraoperative assessment included the type of anesthesia, the time taken for the surgery, blood loss during surgery or any intraoperative complications. The postoperative period was assessed for the number of days of in situ vaginal drain and bladder catheter. Other postoperative event like febrile morbidity, blood transfusion, urinary tract infection was also recorded. The total hospital stay, which included the preoperative workup and the cost of surgery, was recorded.

All necessary permissions were taken from the IEC for conducting the study. Data were entered in Microsoft excel spreadsheet and analyzed with SPSS version 17.0 (Chicago, IL, USA).Wherever applicable, proportions and mean (SD) were calculated. Chi square test was used a test of significance. $\mathrm{P}$ value of $<0.05$ was considered significant.

\section{Results}

A total of 86 cases where studied. Among these 46 (53.5\%) had undergone NDVH and others LAVH. Out of all LAVH patients 1 each was of LAVH + right salpingo-oophorectomy and LAVH + bilateral salpingo-oophorectomy and 2 was of $\mathrm{LAVH}+$ left salpingo-oophorectomy.

Mean age of patient was $42.5 \pm 5.9$ as shown in Table 1. Fibroid and DUB were the most common indications of hysterectomy in LAVH group while DUB was the most common indication in NDVH group [Table 2].

The average duration of surgery was 172.3 minutes (SD 41.7) hours in LAVH group, and 105.8 minutes (SD 32.9 ) in NDVH patients. Duration of surgery and blood loss in NDVH group was less.

The difference in duration of surgery and loss of blood in LAVH and NDVH was found to be statistically significant with $\mathrm{p}<0.001$ [Table 3].

Bladder injury was found in two cases of NDVH and bowel injury in 1 case of NDVH which was managed by primary repair at the time of surgery [Table 4]. 
Table 1: The comparison of demographic characteristics of study patients with respect to Non descent vaginal hysterectomy NDVH, and Laparoscopic assisted vaginal hysterectomy LAVH.

\begin{tabular}{|l|l|l|l|}
\hline Patients Characteristics & $\begin{array}{l}\text { Laparoscopic assisted } \\
\text { vaginal hysterectomy } \\
\text { LAVH }\end{array}$ & $\begin{array}{l}\text { Non descent vaginal } \\
\text { hysterectomy NDVH }\end{array}$ & Total \\
\hline Number of Patient n (\%) & $40(46.5)$ & $46(53.5)$ & $86(100)$ \\
\hline Mean Age + SD & $43.5(5.7)$ & $41.5(6.2)$ & $42.5(5.9)$ \\
\hline Parity* n (\%) & \multicolumn{3}{|l|}{} \\
\hline 2 & $15(37.5)$ & $17(37.0)$ & $32(37.2)$ \\
\hline 3 & $12(30.0)$ & $11(23.9)$ & $23(26.7)$ \\
\hline 4 & $10(25.0)$ & $13(28.3)$ & $23(26.7)$ \\
\hline 5 & $1(2.5)$ & $2(4.3)$ & $3(3.5)$ \\
\hline 6 & $2(5.0)$ & $3(6.5)$ & $5(5.8)$ \\
\hline
\end{tabular}

* Not significant $\mathrm{p}>0.05$

Table 2: The comparison of pre operative characteristics of the study patients with respect to Non descent vaginal hysterectomy NDVH, and Laparoscopic assisted vaginal hysterectomy LAVH.

\begin{tabular}{|c|c|c|c|c|}
\hline Patients Characteristics & $\begin{array}{l}\text { Laparoscopic } \\
\text { assisted vaginal } \\
\text { hysterectomy } \\
\text { LAVH }\end{array}$ & $\begin{array}{l}\text { Non descent vaginal } \\
\text { hysterectomy NDVH }\end{array}$ & Total & P value \\
\hline $\begin{array}{l}\text { Mean duration Symptoms in } \\
\text { months } \pm \text { S.D }\end{array}$ & $13.5(9.2)$ & $16.7(15.1)$ & $15.2(\mathrm{SD} 12.7)$ & 0.249 \\
\hline $\begin{array}{l}\text { Mean Size of Uterus in weeks } \pm \\
\text { S.D }\end{array}$ & $10.2(2.4)$ & $14.3(18.3)$ & 12.4(SD 13.6) & 0.162 \\
\hline \multicolumn{5}{|l|}{ Primary Diagnosis n $(\%)$} \\
\hline Adenomyosis & $12(30.0)$ & $8(17.4)$ & $20(23.3)$ & \multirow[t]{5}{*}{0.718} \\
\hline DUB & $12(30.0)$ & $17(37.0)$ & $29(33.7)$ & \\
\hline Fibroid & $13(32.5)$ & $16(34.8)$ & $29(33.7)$ & \\
\hline PID & $2(5.0)$ & $3(6.5)$ & $5(5.8)$ & \\
\hline Others & $1(2.5)$ & $2(4.3)$ & $3(3.5)$ & \\
\hline \multicolumn{5}{|c|}{ Previous History of surgery present n (\%) } \\
\hline Tubal Ligation & $12(32.5)$ & $35(76.1)$ & $49(55.8)$ & \multirow[t]{4}{*}{0.002} \\
\hline Dilation and curettage & $2(5.0)$ & $1(2.2)$ & $3(3.5)$ & \\
\hline Cholecystectomy & $1(2.5)$ & $2(4.3)$ & $3(3.5)$ & \\
\hline None & $21(52.5)$ & $7(15.2)$ & $28(32.6)$ & \\
\hline \multicolumn{5}{|c|}{ Medical Complication present n (\%) } \\
\hline Hypertension & $3(7.5)$ & $0(0.0)$ & $3(3.5)$ & \multirow[t]{4}{*}{0.074} \\
\hline Diabetes & $0(0.0)$ & $2(4.3)$ & $2(2.3)$ & \\
\hline Others & $0(0.0)$ & $2(4.3)$ & $2(2.3)$ & \\
\hline None & $37(92.5)$ & $42(91.3)$ & $79(91.9)$ & \\
\hline
\end{tabular}


Table 3: The comparison of Intra operative characteristics of the study patients with respect to Non descent vaginal hysterectomy NDVH, and Laparoscopic assisted vaginal hysterectomy LAVH.

\begin{tabular}{|c|c|c|c|c|}
\hline Patients Characteristics & $\begin{array}{l}\text { Laparoscopic } \\
\text { assisted vaginal } \\
\text { hysterectomy } \\
\text { LAVH }\end{array}$ & $\begin{array}{l}\text { Non descent } \\
\text { vaginal } \\
\text { hysterectomy } \\
\text { NDVH }\end{array}$ & $\begin{array}{l}\text { Total } \\
\mathbf{N}(\%)\end{array}$ & $P$ value \\
\hline \multicolumn{5}{|l|}{ Debulking Method n (\%) } \\
\hline Bisection & $12(30.0)$ & $16(34.8)$ & $28(32.6)$ & \multirow[t]{6}{*}{0.237} \\
\hline Bisection/Coring & $2(5.0)$ & $1(2.2)$ & $3(3.5)$ & \\
\hline Bisection/Enucleation & $3(7.5)$ & $7(15.2)$ & $10(11.6)$ & \\
\hline Enucleation & $2(5.0)$ & $4(8.7)$ & $6(7.0)$ & \\
\hline Coring/Enucleation & $0(0)$ & $3(6.5)$ & $3(3.5)$ & \\
\hline None & $21(52.5)$ & $15(32.6)$ & $36(41.9)$ & \\
\hline \multicolumn{5}{|l|}{ Anesthesia n (\%) } \\
\hline General & $40(100.0)$ & $1(2.2)$ & $41(47.7)$ & \multirow[t]{3}{*}{$<0.001$} \\
\hline Subdural & $0(0.0)$ & $44(95.7)$ & $44(51.2)$ & \\
\hline Epidural & $0(0.0)$ & $1(2.2)$ & $1(1.2)$ & \\
\hline Mean Blood loss in $\mathrm{ml} \pm$ S.D & $125.6(51.8)$ & $88.2(35.8)$ & $105.6(\mathrm{SD} 47.6)$ & $<0.001$ \\
\hline $\begin{array}{l}\text { Mean duration of surgery in } \\
\text { minutes } \pm \text { S.D }\end{array}$ & $172.3(41.7)$ & $105.8(32.9)$ & $138.2(\mathrm{SD} 50.0)$ & $<0.001$ \\
\hline
\end{tabular}

Table 4: The comparison of post operative characteristics of the study patients with respect to Non descent vaginal hysterectomy NDVH, and Laparoscopic assisted vaginal hysterectomy LAVH.

\begin{tabular}{|c|c|c|c|c|}
\hline Patients Characteristics & $\begin{array}{l}\text { Laparoscopic } \\
\text { assisted vaginal } \\
\text { hysterectomy LAVH }\end{array}$ & $\begin{array}{l}\text { Non descent vaginal } \\
\text { hysterectomy } \\
\text { NDVH }\end{array}$ & Total & $P$ value \\
\hline $\begin{array}{l}\text { Mean duration of } \\
\text { catheter in days } \pm \text { S.D }\end{array}$ & $1.4(0.5)$ & $1.6(0.5)$ & $1.5(\mathrm{SD} 0.50)$ & 0.086 \\
\hline $\begin{array}{l}\text { Mean duration of Vaginal } \\
\text { drains in days } \pm \text { S.D }\end{array}$ & $1.7(0.8)$ & $2.1(0.9)$ & $1.9(\mathrm{SD} 0.88)$ & 0.023 \\
\hline $\begin{array}{l}\text { Mean duration of } \\
\text { hospitalization in days } \pm \\
\text { S.D }\end{array}$ & $8.2(1.7)$ & $7.9(2.4)$ & 8.1(SD 2.1) & 0.598 \\
\hline \multicolumn{5}{|c|}{ Intra/ Post-operative complications present n (\%) } \\
\hline 1 unit PRBC & $0(0.0)$ & .2) & $1(1.2)$ & \multirow[t]{5}{*}{$<0.001$} \\
\hline Bladder injury & $0(0.0)$ & 2.2) & $1(1.2)$ & \\
\hline Bowel Injury & $1(2.5)$ & 1.2) & $1(1.2)$ & \\
\hline UTI & $1(2.5)$ & $.0)$ & $1(1.2)$ & \\
\hline None & $38(95.0)$ & (95.7) & $82(95.3)$ & \\
\hline
\end{tabular}




\section{Discussion}

This retrospective study from January 2015 to February 2016 shows that both LAVH and NDVH are feasible routes for hysterectomy. $46.5 \%$ patients underwent LAVH and 53.5\% underwent NDVH. Mean age group of NDVH and LAVH group were nearly similar.

More than one third of the patient were para two. This was approximately comparable in NDVH and LAVH group. Most common indication in NDVH group was DUB and fibroid. Most common indication in LAVH group was Fibroid and second most common indication was DUB. The average operating time and the average blood loss was significantly less in NDVH group compared to LAVH group. The intraoperative complication rate was higher in NDVH group with two bladder injuries and one bowel injury. The average operating time, intraoperative blood loss and the cost of surgery were more in the $\mathrm{LAVH}$ group.

The most commonly used debulking method was bisection followed by enucleation and coring. Fibroids up to 14-16 week size were removed by vaginal route. The postoperative fit for discharge time was about 72 hours in both LAVH and NDVH group.

The total hospital stay was more than this time due to inclusion of preoperative workup and scheduling delay due to excessive patient load. LAVH is associated with higher costs [7] and longer duration of operation. It involves a large number of specially trained personnel [8]. NDVH is associated with better outcome with respect to cost duration and intraoperative blood loss. Successful NDVH has been carried out with minimum complications [9.10]. There is a clear advantage of attempting LAVH/ NDVH for benign gynecological conditions. NDVH stands out with the advantage of less operative time, less blood loss, less cost and avoidance of general anesthesia. LAVH offers definite advantage of visualization of uterus and adnexa prior to any operative dissection, thus, minimizing the chances of intraoperative complications like bladder and bowel injury.

\section{Conclusion}

$\mathrm{NDVH}$ is a feasible and safe route of hysterectomy even for fibroids up to 14-16 week size in properly selected patients. LAVH can be seen as a synergistic procedure for cases where prior visualization may help in operative dissection because of additional cost, need of specialized equipment and training and increased intraoperative time and blood loss, LAVH may be reserved for the subset of patients in which operative dissection might be anticipated to be difficult.

Abbreviations: Non descent vaginal hysterectomy $\mathrm{NDVH}$, Laparoscopic assisted vaginal hysterectomy LAVH

Funding: Nil

Conflict of interest: None.

Permission of IRB: Yes

\section{References}

1. Singh KC, Barman SD, Rinku Segupta. Choice of hysterectomy for benign disease, department of obstetrics and gynaecology,University College of medical sciences, Delhi J.Obstet. Gynecol vol-54, july / August 2004:365-370.

2.West S.Drannov P. The hysterectomy Hoax. Doubleday, New York 1994, P 214.

3. Kovac SR. Guidelines to determine the route of hysterectomy. Obstet Gynecol. 1995 Jan;85(1):18-23.

4. Sheth SS.Vaginal hysterectomy. In: PuriR, Malhotra N. eds. Operative Obstetrics and Gynaecology. New Delhi Jaypee brother's medical publishers 2009:499510.

5. Sheth SS, Paghdiwalla K P. In: Saraiya UB, Rao A $\mathrm{K}$, Chateerjee A.eds. Principles and Practice of obstetrics and Gynaecology.2ndedition. New Delhi. Jaypee brother's medical publishers.2003.374-30.

6. Dewan Rupali,Agarwal Shivani,Manisha,Minocha Bharti, Sen Soumendra K. Non-Descent Vaginal Hysterectomy-An Experience. J.Obstet. Gynecol Ind Vol.54,No.4:July/August 2004 Pg 376-378.

7. Meikle SF, NugentSW, Oleans M. Complications and recovery from laparoscopy- assisted vaginal hysterectomy compared with abdominal and vaginal hysterectomy. Obstet Gynecol 1997;89:304-11.

8. Davies A, Vizza E, Bournas N, O'Connor H, Magos A. How to increase the proportion of hysterectomies performed vaginally. Am J Obstet Gynecol. 1998 Oct;179(4):1008-12. 
9. Kumar S, Antony ZK. Vaginal hysterectomy for benign nonprolapsed uterus-initial experience. J Obstet Gynecol Ind 2004;54:60-3.
10. Mazdisnian F, Kurzel RB, Coe S, Bosuk M, Montz F. Vaginal hysterectomy by uterine morcellation: an efficient, non-morbid procedure. Obstet Gynecol. 1995 Jul;86(1):60-4.

\section{How to cite this article?}

Goswami D, Kumari N, Gupta V, Chaudhary P, LAVH versus NDVH for benign gynaecological diseases: an experience in tertiary care hospital in Uttarakhand: Int J Med Res Rev 2016;4(5):679-684.doi: 10.17511/ijmrr.2016.i05.02. 